\title{
ŠIUOLAIKINĖS BRONCHOSKOPIJOS GALIMYBĖS
}

\author{
GUODA PILKAUSKAITĖ, DR. MARIUS ŽEMAITIS \\ KMU PULMONOLOGIJOS IR IMUNOLOGIJOS KLINIKA
}

\begin{abstract}
Reikšminiai žodžiai: bronchologija, endoskopinè diagnostika ir gydymas, autofluorescencinė bronchoskopija, endoskopinis ultragarsas.

Santrauka. Bronchoskopija - vienas svarbiausių invazinių tyrimo metodų pulmonologijoje. Atsiradus nauju bronchų tyrimų metodų jos svarbą kasdienėje praktikoje dar labiau padidejjo. Straipsnyje aptariama bronchologijos istorija, fibrobronchoskopo (lanksčiojo) ir rigidinio (standžiojo) bronchoskopo panaudojimo galimybès, autofluorescencinė bronchoskopija ir endoskopinis ultragarsinis tyrimas bei kvejpavimo takų stenozės gydymas.
\end{abstract}

\section{IŠ BRONCHOLOGIJOS ISTORIJOS}

Žinoma, kad jau Hipokratas (460-370 m. pr. Kr.) siūlè gelbèti dūstantị žmogụ, ikkišant vamzdeli i kvèpavimo takus, tačiau Porteris dar 1838 metais rašé, kad „tikriausiai nèra kitos medicinos srities, apgaubtos didesne tamsa ir keliančios daugiau sunkumu gydytojui nei gerklu ir trachèjos ligos" [1]. Instrumentai, skirti kitoms kūno ertmèms apžiūrèti, kaip antai: rektoskopas, otoskopas, medicinoje naudojami daugeli šimtmečių, o bronchoskopijos era prasidejo tik devyniolikto amžiaus antroje pusejje, kai ausŭ, nosies ir gerklès ligu profesorius Gustav Killian, dirbęs Vokietijoje, Freiburgo universitete, 1887 metais atliko pirmąją bronchoskopiją rigidiniu (standžiu) bronchoskopu per gerklas. Jis greitai išgarsèjo visame pasaulyje kaip naujo svetimkūniu pašalinimo iš kvejpavimo takų būdo išradèjas. Būtent profesorius Gustav Killian laikomas bronchoskopijos „tèvu“ [1].

Kitas svarbus žingsnis bronchologijoje - lanksčiojo bronchoskopo (fibrobronchoskopo) išradimas. Tai japonu gydytojo Shigeto Ikeda (1925-2001), dirbusio Kejo universitete, idejja [1]. Sparčiai patobulejus elektronikai, 1987 metais buvo pagamintas vaizdo bronchoskopo prototipas, o tai sudare sąlygas matyti aiškų padidintą endoskopini vaizdą spalvotame ekrane. Šis išradimas greitai paplito visame pasaulyje ir dabar yra svarbi diagnostikos ir mokomoji priemoné universitetinèse ligoninèse.

\section{FIBROBRONCHOSKOPIJOS GALIMYBĖS}

Šiandien fibrobronchoskopija yra vienas svarbiausių invaziniu tyrimo metodu pulmonologijoje. Sukèlus vietinę nejautrą, lanksčiuoju bronchoskopu apžiūrima balso plyšys, trachẻja ir bronchinis medis iki segmentinių ir subsegmentinių bronchų. Apžiūros metu vertinama kvẻpavimo takụ anatomija, praeinamumas, gleivinès pokyčiai, bronchų sekreto pobūdis bei kiekis.
Atsižvelgiant ị ịtariamą patologiją bei endoskopinius radinius, tyrimo metu paimama medžiagos papildomiems tyrimams: bronchų išplovų mikrobiologiniams bei citologiniams tyrimams, bronchų nuobrūžŭ, bronchụ ir alveoliụ išplovų (BAL), plaučiu audinio biopsija. Radiologiniu tyrimu nustačius plaučiu piešinio difuzinių pokyčiu, diseminaciją ar periferinių lokalių darinių, atliekama transbronchinè biopsija kontroliuojant rentgenu.

Nustačius radiologinių pokyčių kvèpavimo takų sienelèse, plaučiu parenchimoje ar tarpuplaučio struktūrose, esančiose greta tracheobronchinio medžio, galima atlikti transbronchinę adatinę aspiraciją. Prieš procedūrą būtina gerai išnagrinèti krūtinès ląstos rentgenogramą arba kompiuterinę tomogramą. Jei reikia, procedūrą galima kontroliuoti rentgenu. Adatos ilgis ir storis parenkamas pagal pokyčių lokalizaciją ir pageidaujamą morfologini tyrimą [2].

\section{BRONCHOSKOPIJA RIGIDINIU BRONCHOSKOPU ŠIANDIEN}

Šiuolaikinis rigidinis (standus) bronchoskopas yra tiesus, tuščiaviduris, maždaug $40 \mathrm{~cm}$ ilgio ir 9-13,5 $\mathrm{mm}$ skersmens metalinis vamzdis. Jo distalinis galas nuožulnus, kad instrumentą būtụ lengviau prastumti pro balso plyšị bei patologiškai susiaurèjusias trachẻjos vietas. Kai kuriais atvejais nuožulnusis galas gali būti panaudotas trachëjos spindyje esančio darinio rezekcijai. Proksimaliniame gale yra angos, pro kurias ikišami ar prijungiami procedūrai reikalingi instrumentai: dirbtinés plaučių ventiliacijos aparatas (pvz., JET ventiliacija), siurblys, šviesos šaltinis, vaizdo kamera, žnyplès biopsijai, įrankiai svetimkūniams šalinti ir kitos priemonès, kuriu naudojimas priklauso nuo pačios procedūros tikslo (1 lentelè). Atliekant bronchoskopiją rigidiniu (standžiu) bronchoskopu gali būti naudojamas fibrobronchoskopas, pavyzdžiui, skiltiniams ar segmentiniams bronchams apžiūrèti, mas standžiu bronchoskopu galima ivertinti tik pagrindinius bronchus. 
1 lentelè. FIBROBRONCHOSKOPIJOS IR RIGIDINĖS BRONCHOSKOPIJOS PANAUDOJIMO GALIMYBĖS (ADAPTUOTA PAGAL 4)

\begin{tabular}{|c|c|}
\hline Fibrobronchoskopija & $\begin{array}{l}\text { Bronchoskopija rigidiniu } \\
\text { (standžiu) bronchoskopu }\end{array}$ \\
\hline $\begin{array}{l}\text { Diagnostinė: } \\
\text { - endobronchinè biopsija } \\
\text { - transbronchinè biopsija } \\
\text { - transbronchinè adatinè aspira- } \\
\text { cija } \\
\text { - endobronchinis ultragarsinis } \\
\text { tyrimas } \\
\text { Gydomoji: } \\
\text { - procedūros žnyplèmis, gaudo- } \\
\text { maisiais maišeliais (svetimkūnių } \\
\text { šalinimas) } \\
\text { - balioninè dilatacija } \\
\text { - lazeris } \\
\text { - koaguliacija argonplazma } \\
\text { - elektrokaustika } \\
\text { - } \text { endodinaminè terapija } \\
\text { - endobronchinè krioterapija } \\
\text { - stentavimas }\end{array}$ & $\begin{array}{l}\text { Procedūros žnyplèmis, } \\
\text { gaudomaisiais maišeliais } \\
\text { (svetimkūnių šalinimas) } \\
\text { Balioninė ir rigidinė dilatacija } \\
\text { Lazeris } \\
\text { Koaguliacija argonplazma } \\
\text { Elektrokaustika } \\
\text { Fotodinaminė terapija } \\
\text { Endobronchinė krioterapija } \\
\text { Endobronchinė brachiterapija } \\
\text { Stentavimas }\end{array}$ \\
\hline
\end{tabular}

Bronchoskopija rigidiniu (standžiu) bronchoskopu atliekama sukèlus bendrąją nejautrą, todèl šiai procedūrai reikalinga visa kvalifikuotu specialistų komanda: ne tik bronchologas, medicinos seserys, pagalbinis personalas, bet ir patyręs anesteziologas.

Ilgą laiką rigidinis (standus) bronchoskopas buvo vienintelis instrumentas, pritaikytas diagnostinèms ir gydomosioms kvėpavimo takų procedūroms. Sukūrus lankstų bronchoskopą, standžiosios bronchoskopijos vieta pulmonologijoje pasikeitè. Šiandien ji taikoma gausiam kraujavimui iš kvėpavimo takų stabdyti, piktybinès ir nepiktybinès kilmès trachejos ir bronchų stenozei gydyti, kvejpavimo takams stentuoti, svetimkūniams šalinti [3]. Taigi bronchoskopija rigidiniu (standžiu) bronchoskopu yra neatsiejama šiandieninès bronchologijos dalis.

\section{AUTOFLORESCENCINE் BRONCHOSKOPIJA}

Autoflorescencinès bronchoskopijos metu tam tikro ilgio šviesos bangos siunčiamos tiriamos anatominès struktūros link ir atsispindèjusios nuo endogeninių fluoroforu surenkamos bei paverčiamos spalvotu vaizdu ekrane. Nepakitę audiniai švyti žalia šviesa, o raudonai ruda rodo sumažèjusią atspindejjimo galią. Raudonai rudos spalvos vaizdas būdingas ikinavikiniams arba ankstyviems piktybiniams pažeidimams dèl epitelio sustorèjimo ar naviko neovaskuliarizacijos sumažejja atspindejjimo galia [4]. Autoflorescencinès bronchoskopijos tikslas - nustatyti ikinavikinius ar pradinius piktybinius kvejpavimo takų gleivinès pokyčius, kurie nematomi iprastinès baltos šviesos bronchoskopijos metu.

Atlikta nemažai tyrimų, kuriais įrodyta, kad autoflorescencinès bronchoskopijos jautrumas nustatant ikinavikinius ir piktybinius pokyčius du kartus didesnis nei baltos šviesos [5]. Šiandien autofluorescencinę bronchoskopiją rekomenduojama atlikti radus netipinių ląstelių skrepliuose, prieš operaciją tiriant pacien- tus, kuriems nustatytas plaučių vẻžys, tiriant pacientus po radikalios plaučių vėžio rezekcijos, esant ankstyvam centriniam plaučiui véžiui ir planuojant radikalų endobronchini gydymą, taip pat stebint ikinavikinių pokyčių centriniuose kvėpavimo takuose kaitą [5].

\section{ENDOBRONCHINIS ULTRAGARSINIS TYRIMAS}

Tiriant ultragarsu vizualizuojama tracheobronchine sienelè bei aplink ją esančios struktūros: limfmazgiai, kraujagyslès, navikiniai dariniai. Šiuo metu naudojami ultragarsiniai bronchoskopai (sektoriniai ir radialiniai) ir (ar) ultragarsiniai davikliai. İkišus ultragarsinị fibrobronchoskopą arba ultragarsinị daviklį, tiriamų struktūruc projekcijoje pripildomas balionas - taip susidaro glaudus kontaktas tarp daviklio ir broncho sienelès. Ultragarso banga siunčiama anatominių struktūrų link. Atsispindejusios bangos verčiamos elektros signalu ir vizualizuojamos ekrane. Ultragarsas padeda atskirti naviko įaugimą nuo gretimų struktūrų spaudimo iš išorès ar sąlyčio su jomis, taip pat ịvertinti neoplazinio įaugimo gyli. Manoma, kad ateityje endobronchiniu ultragarsiniu tyrimu galètų būti nustatoma karcinoma in situ [4].

Viena iš svarbiausių endobronchinio ultragarsinio tyrimo sričių - tarpuplaučio limfmazgių diagnostika. Tiriant šiuolaikiniais bronchoskopais galima vienu metu matyti ultragarsinị tarpuplaučio struktūrų vaizdą, jei reikia, ijungti ir doplerio funkciją kraujotakai vertinti bei punktuoti reikiamas struktūras plona specialia ultragarsine adata, ileista per bronchoskopo kanalą. Apibendrinus paskelbtų perspektyviųjų tyrimų duomenis, paaiškejjo, kad endobronchiniu ultragarsu kontroliuojamų transbronchinių tarpuplaučio limfmazgiu punkcijų nustatant padidejjimo priežastị jautrumas buvo 85-95,7 proc., specifiškumas - 100 proc. $[6,7,8]$.

Šiuo metu vykdomi klinikiniai tyrimai, kuriais lyginami mediastinoskopija nustatyti limfmazgių morfologinių pokyčių duomenys su endobronchinio ir endoezofaginio ultragarso procedūrų (EBUS ir EUS) metu atliktų limfmazgiu punkcijų duomenimis. Prognozuojama, kad ateityje EBUS ir EUS procedūru derinys užims mediastinoskopijos vietą plaučių véžio diagnostikos algoritme $[4,9,10]$.

\section{BRONCHOSKOPINIAI KVËPAVIMO TAKŲ STE- NOZĖS GYDYMO BŪDAI}

Viena iš dažniausių indikacijų gydomajai bronchoskopijai atlikti yra stambiųjų kvėpavimo takų (trachèjos, pagrindinių bronchų bei intermedinio broncho) stenozių šalinimas.

Stambiưjų kvėpavimo takų stenozė gali būti piktybinès (pvz., pirminè bronchų karcinoma) ir nepiktybinès (pvz., stenozė po ilgalaikès intubacijos, amiloidozè, uždegimo pokyčiai) kilmès. Tokia stenozė gali būti besimptomè iki tol, kol susiaurès iki kritinio diametro, t. y. 5-8 mm. Stenozès diagnozė nustatoma, ịvertinus ligos anamnezę, objektyvaus tyrimo duomenis (girdimas 
stridoras, kvėpavimo funkcijos nepakankamumo požymiai) bei atlikus radiologinius tyrimus (kompiuterinę tomografiją) bei diagnostinę bronchoskopiją. Gydymo procedūra bei priemonès turètų būti parinktos pagal klinikinę situaciją, stenozès kilmę bei tipą, indikacijas bei kontraindikacijas atlikti rigidinę (standžiąją) bei fibrobronchoskopiją ir personalo patirtị bei kvalifikaciją.

Šiuo metu pasaulyje naudojama daug priemoniu kvėpavimo takų stenozėms gydyti. Gerybinès stenozès atveju chirurginis gydymas iki šiol tebèra auksinis standartas. Bronchologinès priemonès - tai lazeris, elektrokaustika, koaguliacija argonplazma, fotodinaminè terapija, brachiterapija, krioterapija [4]. Šių priemoniu lyginamieji duomenys pateikti 2 lenteleje. Be to, gali būti taikoma balioninè arba rigidinè dilatacija bei stentavimas. Kvėpavimo takai klinikinëje praktikoje pradèti stentuoti maždaug prieš 100 metų. Šiandien stentai naudojami centrinių kvẻpavimo takų spindžiui atkurti, esant spaudimui iš išorès arba striktūrai, suminkštejjusioms kremzlèms prilaikyti trachoebronchinès maliacijos atveju bei fistulèms, jungiančioms trachejją su stemple, tarpuplaučiu arba pleuros ertme, uždaryti. Pagal medžiagą, iš kurios gaminami, stentai skiriami ì keturias grupes: polimerinius, metalinius, dengtus metalo bei mišrius. Piktybinio auglio atvejais, siekiant apsaugoti nuo navikinių masių íaugimo, turètų būti naudojami polimeriniai arba dengti metalo stentai, tačiau procedūros rezultatai labiau priklauso nuo biomechaninių stento savybių nei nuo medžiagos, iš kurios jis pagamintas. Stentai gaminami tiesūs, $Y$ formos, $T$ formos, $J$ formos arba derinamos kelios formos [11]. Stento forma, dydis ir ilgis turi būti kruopščiai parenkami individualiai. Visais atvejais reikètų rinktis tokị stentą, kurị, esant reikalui, būtų galimą pašalinti.

Prieš stento įdejjimą reikia pakankamai išplèsti susiaurejusius kvèpavimo takus. Tam naudojama balioninè ar rigidinė dilatacija (bužavimas). Po tokios procedūros kiekvienam pacientui turètų būti duodamas specialus pasas su duomenimis apie stentą, jo įdejjimo datą bei koks intubacinis vamzdelis turi būti naudojamas, iškilus skubios intubacijos būtinybei.

\section{APIBENDRINIMAS}

Bronchologija - sparčiai besivystanti invazinės pulmonologijos dalis, atverianti naujas galimybes sėkmingai diagnozuoti ir gydyti plaučių ligas. Laikas ir tolesni tyrimai parodys, kurie metodai išsikovos pozicijas kasdienejje praktikoje, o kurie liks tik istorija.

\section{LITERATŪRA}

1. Becker R B, Marsh B R. History of Rigid Bronchoskope. Interventional Pulmonology. Prog Respir Res. Basel, Karger, 2000; 30:2-15.

2. Bolliger CT, Mathur P N et al. ERS/ATS Statement on Interventional Pulmonology. Eur Respir J 2002; 19:356-373.

3. Beamis J F. Modern Use of Rigid Bronchoskopy. Interventional Pulmonology. Prog Respir Res. Basel, Karger, 2000; 30: 22-30.
2 lentelè. BRONCHOSKOPINIAI KVÉPAVIMO TAKŲ STENOZĖS GYDYMO BŪDAI (ADAPTUOTA PAGAL 4)

\begin{tabular}{|c|c|c|c|c|}
\hline $\begin{array}{l}\text { Priemo- } \\
\text { né }\end{array}$ & $\begin{array}{l}\text { Mechaniz- } \\
\text { mas }\end{array}$ & Poveikis & $\begin{array}{l}\text { Privalu- } \\
\text { mai }\end{array}$ & Trūkumai \\
\hline Lazeris & $\begin{array}{l}\text { Šiluminè la- } \\
\text { zerio šviesos } \\
\text { energija }\end{array}$ & $\begin{array}{l}\text { Audinio ko- } \\
\text { aguliacija ir } \\
\text { išgarinimas }\end{array}$ & $\begin{array}{l}\text { Greitas } \\
\text { poveikis }\end{array}$ & $\begin{array}{l}\text { Brangus, } \\
\text { sudetingas } \\
\text { ìrenginys }\end{array}$ \\
\hline $\begin{array}{l}\text { Elektro- } \\
\text { kaustika }\end{array}$ & $\begin{array}{l}\text { Šiluminė } \\
\text { elektros sro- } \\
\text { vès energija }\end{array}$ & $\begin{array}{l}\text { Audinio } \\
\text { koaguliacija, } \\
\text { bet poveikis } \\
\text { labiau pavir- } \\
\text { šutinis nei } \\
\text { lazerio }\end{array}$ & $\begin{array}{l}\text { Saugus, } \\
\text { nebran- } \\
\text { gus }\end{array}$ & $\begin{array}{l}\text { Dèl reikalingo } \\
\text { tampraus } \\
\text { sąlyčio, } \\
\text { procedūros } \\
\text { metu dažnai } \\
\text { tenka valyti } \\
\text { instrumentą }\end{array}$ \\
\hline $\begin{array}{l}\text { Koagu- } \\
\text { liacija } \\
\text { argon- } \\
\text { plazma }\end{array}$ & $\begin{array}{l}\text { Šiluminė } \\
\text { energija, } \\
\text { atsiradusi } \\
\text { sąveikau- } \\
\text { jant argono } \\
\text { dujoms su } \\
\text { elektros } \\
\text { srove }\end{array}$ & $\begin{array}{l}\text { Paviršinè } \\
\text { audinio koa- } \\
\text { guliacija }\end{array}$ & $\begin{array}{l}\text { Jokio } \\
\text { nepagei- } \\
\text { daujamo } \\
\text { poveikio } \\
\text { gilie- } \\
\text { siems } \\
\text { audi- } \\
\text { niams }\end{array}$ & $\begin{array}{l}\text { Poveikis tik } \\
\text { paviršiniams } \\
\text { audiniams }\end{array}$ \\
\hline $\begin{array}{l}\text { Fotodi- } \\
\text { naminè } \\
\text { terapija }\end{array}$ & $\begin{array}{l}\text { Fotosensibi- } \\
\text { lizacija }\end{array}$ & $\begin{array}{l}\text { Vèlyva } \\
\text { audinio des- } \\
\text { trukcija (po } \\
24-48 \text { val.) }\end{array}$ & $\begin{array}{l}\text { Palyginti } \\
\text { ilgai } \\
\text { trun- } \\
\text { kantis } \\
\text { efektas }\end{array}$ & $\begin{array}{l}\text { Brangus, } \\
\text { reikia kartoti } \\
\text { procedūras, } \\
\text { odos fotosen- } \\
\text { sibilizacija } \\
\text { užtrunka iki } \\
6 \text { sav. }\end{array}$ \\
\hline $\begin{array}{l}\text { Brachi- } \\
\text { terapija }\end{array}$ & $\begin{array}{l}\text { Tiesioginis } \\
\text { jonizuo- } \\
\text { jančiosios } \\
\text { spinduliuo- } \\
\text { tės poveikis } \\
\text { kvėpavimo } \\
\text { takams }\end{array}$ & $\begin{array}{l}\text { Vèlyva pikty- } \\
\text { binio audinio } \\
\text { destrukcija }\end{array}$ & $\begin{array}{l}\text { Ilgalaikis } \\
\text { efektas, } \\
\text { galima } \\
\text { derinti su } \\
\text { išorine } \\
\text { spindu- } \\
\text { liuote }\end{array}$ & $\begin{array}{l}\text { Padidèja } \\
\text { komplikacijų } \\
\text { rizika, ypač } \\
\text { kraujavimo }\end{array}$ \\
\hline $\begin{array}{l}\text { Kriote- } \\
\text { rapija }\end{array}$ & $\begin{array}{l}\text { Audinio } \\
\text { destrukcija, } \\
\text { kurią sukelia } \\
\text { cikliškas } \\
\text { audinio at- } \\
\text { šaldymas iki } \\
\text { ekstremalios } \\
\text { tempera- } \\
\text { tūros ir } \\
\text { atšildymas }\end{array}$ & $\begin{array}{l}\text { Vèlyva audi- } \\
\text { nio destruk- } \\
\text { cija (po 1-2 } \\
\text { savaičių) }\end{array}$ & $\begin{array}{l}\text { Tin- } \\
\text { kamas } \\
\text { svetim- } \\
\text { kūniams, } \\
\text { dide- } \\
\text { liems } \\
\text { gleivinès } \\
\text { kamš- } \\
\text { čiams ir } \\
\text { kt. šalinti }\end{array}$ & $\begin{array}{l}\text { Netinka ūmi- } \\
\text { nei kvėpavimo } \\
\text { takų obstruk- } \\
\text { cijai šalinti. } \\
\text { Procedūras } \\
\text { reikia kartoti }\end{array}$ \\
\hline
\end{tabular}

\section{CONTEMPORARY BRONCHOSCOPY POSSIBILITIES}

\section{GUODA PILKAUSKAITĖ, MARIUS ŽEMAITIS \\ DEPARTMENT OF PULMONOLOGY AND IMMUNOLOGY KAUNAS UNIVERSITY OF MEDICINE}

Key words: bronchology, endoscopic diagnostics and treatment, autoflorescence bronchoskopy, endoscopic ultrasound.

Summary. Bronchology is one of the most important parts of inerventional pulmonology, that focuses on diagnostics and treatment of malignant and nonmalignant respiratory system disorders. The variety of new scopes and technological innovations has enhansed its importance in everyday practice. History of bronchology, the possibilities to use rigid and flexible bornchoscopes, the place of autoflorescence bronchoscopy and endocsopic utrasound in nowadays pulmonology and the management of airway stenoses are discussed in this article. 